\title{
Do we miss the hot spots? - The use of very high resolution aerial photographs to quantify carbon fluxes in peatlands
}

\author{
T. Becker ${ }^{1}$, L. Kutzbach ${ }^{1}$, I. Forbrich ${ }^{1}$, J. Schneider ${ }^{1}$, D. Jager ${ }^{1}$, B. Thees ${ }^{2}$, and M. Wilmking ${ }^{1}$ \\ ${ }^{1}$ Institute of Botany and Landscape Ecology, University of Greifswald, Grimmer Straße 88, 17487 Greifswald, Germany \\ ${ }^{2}$ Federal Environmental Agency, Berlin, Germany
}

Received: 25 January 2008 - Published in Biogeosciences Discuss.: 6 March 2008

Revised: 1 August 2008 - Accepted: 26 August 2008 - Published: 6 October 2008

\begin{abstract}
Accurate determination of carbon balances in heterogeneous ecosystems often requires the extrapolation of point based measurements. The ground resolution (pixel size) of the extrapolation base, e.g. a land-cover map, might thus influence the calculated carbon balance, in particular if biogeochemical hot spots are small in size. In this paper, we test the effects of varying ground resolution on the calculated carbon balance of a boreal peatland consisting of hummocks (dry), lawns (intermediate) and flarks (wet surfaces). The generalizations in lower resolution imagery led to biased area estimates for individual micro-site types. While areas of lawns and hummocks were stable below a threshold resolution of $\sim 60 \mathrm{~cm}$, the maximum of the flark area was located at resolutions below $25 \mathrm{~cm}$ and was then decreasing with coarsening resolution. Using a resolution of $100 \mathrm{~cm}$ instead of $6 \mathrm{~cm}$ led to an overestimation of total $\mathrm{CO}_{2}$ uptake of the studied peatland area (approximately $14600 \mathrm{~m}^{2}$ ) of $\sim 5 \%$ and an underestimation of total $\mathrm{CH}_{4}$ emission of $\sim 6 \%$. To accurately determine the surface area of scattered and small-sized micro-site types in heterogeneous ecosystems (e.g. flarks in peatlands), a minimum ground resolution appears necessary. In our case this leads to a recommended resolution of $25 \mathrm{~cm}$, which can be derived by conventional airborne imagery. The usage of high resolution imagery from commercial satellites, e.g. Quickbird, however, is likely to underestimate the surface area of biogeochemical hot spots. It is important to note that the observed resolution effect on the carbon balance estimates can be much stronger for other ecosystems than for the investigated peatland. In the investigated peatland the relative hot spot area of the flarks is very small and their hot spot characteristics with respect to $\mathrm{CH}_{4}$ and $\mathrm{CO}_{2}$ fluxes is rather modest.
\end{abstract}

\section{Introduction}

Closed chambers have been frequently used to derive gas exchange balances between ecosystems and the atmosphere. Usually, representative plots within the ecosystem are selected, which cover the spatial heterogeneity of the study site. There, fluxes are measured, and the modeled seasonal gas exchange fluxes from these plots are extrapolated to larger areas or the whole ecosystem. Extrapolation is usually done based on the spatial representation of each measured microsite within the ecosystem: a modeled flux of a particular representative micro-site is usually multiplied by the area that particular micro-site type occupies (Schimel and Potter, 1995).

The exact spatial distribution of micro-sites is particularly important if micro-site size is small and the ecosystem surface strongly heterogeneous, e.g. in many peatland ecosystems. Spatial information on micro-site distribution can be obtained by rough estimation, vegetation mapping in a smaller area e.g. Riutta et al. (2007), along transects e.g. Alm et al. (1997) and Laine et al. (2006), or with a landcover map of the complete area under study e.g. Bubier et al. (2005). While the first approaches cover just a fraction of the study area and do not necessarily represent the situation in the whole study area, this last approach promises the most reliable spatial estimates and thus the most reliable flux extrapolation. Land-cover maps are more applicable regarding a complete and representative coverage of heterogenous areas. However, it depends entirely on the relationship between the ground resolution of the imagery and the size of the micro-sites. Here, we show that ecosystem trace gas flux estimates, especially for methane, depend significantly on the resolution of the underlying land-cover map.

\section{Correspondence to: $\mathrm{T}$. Becker}

(tbecker@uni-greifswald.de)

Published by Copernicus Publications on behalf of the European Geosciences Union. 


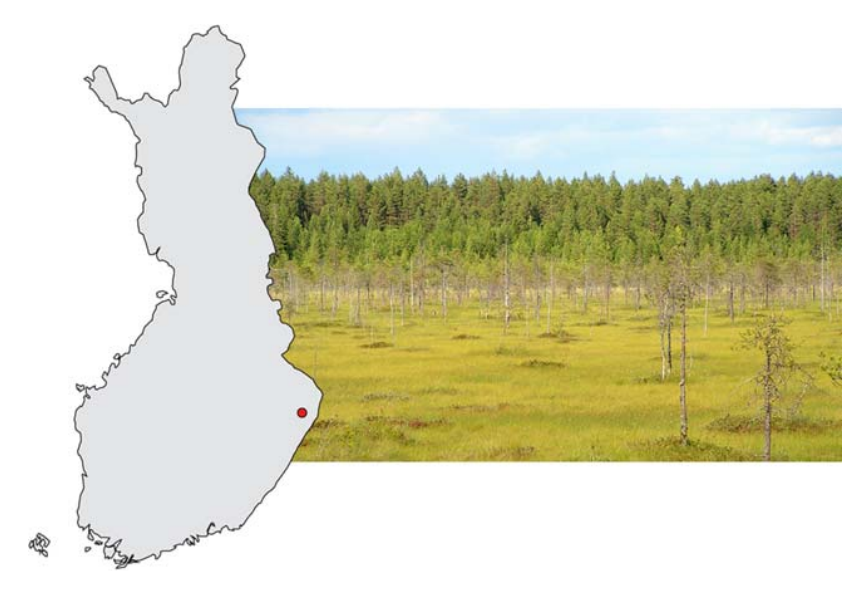

Fig. 1. Location of the study site in Finland, indicated by the red point.

\section{Study site}

The peatland "Salmisuo" is located at $62^{\circ} 47^{\prime} \mathrm{N}, 30^{\circ} 56^{\prime} \mathrm{E}$, in Eastern Finland (Fig. 1), and is generally classified as an oligotrophic low-sedge pine fen (Saarnio et al., 1997). Climatic conditions represent the boreal forest climate (Strahler and Strahler, 2005) with a mean annual air temperature of $+2.1^{\circ} \mathrm{C}$ and a mean annual precipitation of $667 \mathrm{~mm}$ (years: 1971-2000 in Finnish Meteorological Institute, 2002). The surface of the peatland consists of three main vegetation communities, which follow the microtopography. Hummocks are elevated and drier areas (Pinus sylvesteris, Andromeda polifolia, Sphagnum fuscum), lawns are intermediate areas with respect to moisture conditions (Eriophorum vaginatum, Sphagnum balticum, Sphagnum papillosum), and flarks are wet areas (Scheuchzeria palustris, Sphagnum balticum).

\section{Methods}

The calculated carbon balance for this study is based on (1) plot-scale quantification of carbon dioxide $\left(\mathrm{CO}_{2}\right)$ and methane $\left(\mathrm{CH}_{4}\right)$ exchange fluxes using closed chambers over 50 days, (2) a hydrological part to estimate the lateral carbon losses by dissolved organic carbon (DOC) and 3) a remote sensing part to map the spatial distribution of micro-sites.

\subsection{Gas flux measurements and carbon budget calculation}

For this study, we analyzed $\mathrm{CO}_{2}$ and $\mathrm{CH}_{4}$ emission for the time period 26 July 2005-13 September 2005 (50 days): fluxes of $\mathrm{CO}_{2}$ and $\mathrm{CH}_{4}$ were measured with the closed chamber technique (Kutzbach et al., 2007a; Saarnio et al., 1997).

Sample plots have been chosen by the three dominant types of micro-sites (flarks, lawns and hummocks). For every micro-site type four replicate sample plots have been selected to develop micro-site emission models covering the spatial variability within the micro-site type.

$\mathrm{CO}_{2}$ and $\mathrm{CH}_{4}$ fluxes were measured once a week. The $\mathrm{CO}_{2}$ measurements were performed over $24 \mathrm{~h}$. For determination of net ecosystem $\mathrm{CO}_{2}$ exchange, we employed a transparent chamber $(60 \mathrm{~cm} \times 60 \mathrm{~cm} \times 32 \mathrm{~cm})$ with an automatic cooling system which kept the headspace air temperature within approximately $1^{\circ} \mathrm{C}$ of the ambient temperature. The $\mathrm{CH}_{4}$ flux measurements were conducted using aluminum chambers. The $\mathrm{CO}_{2}$ concentrations were measured using a $\mathrm{CO}_{2} / \mathrm{H}_{2} \mathrm{O}$ infrared gas analyzer (LI-840, Licor, USA). $\mathrm{CO}_{2}$ readings were taken at $1 \mathrm{~s}$ intervals over $120 \mathrm{~s}$. During the $\mathrm{CH}_{4}$ flux measurements, four headspace samples were taken every $4 \mathrm{~min}$ from the chamber in a 16 min time period. $\mathrm{CH}_{4}$ concentration in the syringes were analyzed one day after sampling with a gas chromatograph (Shimadzu 14A) equipped with a flame ionisation detector. The gas fluxes were calculated from the concentration increase in the chamber headspace over time applying nonlinear exponential regression for $\mathrm{CO}_{2}$ (Kutzbach et al., 2007a) and linear regression for $\mathrm{CH}_{4}$.

The seasonal exchange was calculated using models which have been developed for the research site: in case of $\mathrm{CH}_{4}$, we applied a non-linear function with peat temperature in $20 \mathrm{~cm}$ depth and water table as predictor variables (Saarnio et al., 1997) and subsequently tested for their significance. Due to insignificance of the influence of the water table we used the following formula:

$F_{\mathrm{CH} 4}=\exp \left(a_{1}+a_{2} \times T_{\text {peat }}\right)$,

where $a_{1}$ and $a_{2}$ are fitting parameters and $T_{\text {peat }}$ is the peat temperature in $20 \mathrm{~cm}$ depth.

The $\mathrm{CO}_{2}$ exchange fluxes were modelled by a nonlinear function of the form:

$F_{\mathrm{CO} 2}=\frac{b_{1} \times T_{\text {air }} \times \mathrm{PAR}}{b_{2}+\mathrm{PAR}}+b_{3} \times \exp \left(b_{4} \times T_{\text {air }}\right)$,

where $T_{\text {air }}$ is air temperature, PAR is photosynthetically active radiation and $b_{1}, b_{2}, b_{3}$ and $b_{4}$ are fitting parameters. The first part of the equation including the parameters $b_{1}$ and $b_{2}$ represents the control of micro-site photosysthesis (Kettunen, 2000), the second part with the parameters $b_{3}$ and $b_{4}$ represents the control of micro-site respiration (Kutzbach et al., 2007b).

Contrasting the results by Saarnio et al. (1997) the model did not explain the hummock emissions significantly (Table 1).

Hence hummock emission was calculated by monthly mean emission. Finally, the modelled time series were integrated to derive the total amount emitted over the 50-day investigation period.

\subsection{Dissolved organic carbon export}

Dissolved organic carbon (DOC) export was calculated by multiplying daily surface runoff with average daily DOC 
Table 1. Model characteristics of Eqs. 1 and 2 where $n$ is the number of samples, $b_{1}-b_{4}$ and $a_{1}, a_{2}$ are fitting parameters, \pm is the $95 \%$ confidence interval of the fitting parameters, $r^{2}$ is the coefficient of determination and $\sigma_{\text {res }}$ is the standard deviation of the residuals.

\begin{tabular}{llllllllllll}
\hline $\mathrm{CO}_{2}$ & & & & & & & & & & \\
& $n$ & $b_{1}$ & \pm & $b_{2}$ & \pm & $b_{3}$ & \pm & $b_{4}$ & \pm & $r^{2}$ & $\sigma_{\text {res }}$ \\
\hline flarks & 100 & -12.21 & 1.52 & 254.70 & 103.76 & 11.91 & 5.53 & 0.11 & 0.03 & $0.87^{* * *}$ & 24.82 \\
lawns & 103 & -20.98 & 3.03 & 315.82 & 131.07 & 7.07 & 3.78 & 0.16 & 0.03 & $0.85^{* * *}$ & 40.40 \\
hummocks & 104 & -27.43 & 5.29 & 336.74 & 190.78 & 24.02 & 17.06 & 0.10 & 0.04 & $0.77^{* * *}$ & 73.73 \\
\hline $\mathrm{CH}_{4}$ & & & & & & & & & & & \\
& $n$ & $a_{1}$ & \pm & $a_{2}$ & \pm & & & & & $r^{2}$ & \\
\hline flarks & 8 & 2.65 & 0.88 & 0.14 & 0.06 & & & & & $0.87^{* *}$ & 8.62 \\
lawns & 9 & 2.23 & 1.41 & 0.11 & 0.10 & & & & & $0.55^{*}$ & 7.91 \\
hummocks & 8 & - & - & - & - & & & & & - & - \\
\hline
\end{tabular}

*** $p<0.001,{ }^{* *} p<0.01,{ }^{*} p<0.05$

mass per volume concentrations ([DOC]); measurements were undertaken at a ditch collecting the peatland outflow. [DOC] was determined by daily water sampling and subsequent analysis of UV absorbance at $254 \mathrm{~nm}$ in a double beam UV/VIS spectrophotometer. For calibration of the UV/VIS spectrophotometer, a selection of samples was analyzed with a Shimadzu 5000-A TOC analyzer for their [DOC] to establish a linear regression function between UV absorption and [DOC]. Discharge was measured by a sharp-crested v-notch weir. Discharge values were logged every $15 \mathrm{~min}$ and subsequently integrated to daily runoff values. The resulting daily DOC flux rates in the stream were converted to export values per unit area (in $\mathrm{g} \mathrm{C} / \mathrm{m}^{2}$ ) through integration over time and then divided by the catchment area size $\left(365000 \mathrm{~m}^{2}\right)$.

\subsection{Remote sensing}

The remote sensing task was covered by very high resolution imagery taken from a helium filled dirigible on 10 August 2006. The dirigible with a volume of $2 \mathrm{~m}^{3}$ was capable to lift $1 \mathrm{~kg}$ of payload and was with its tail fins well equipped to be more stable in the air than a balloon (Fig. 2). At the bottom of the dirigible, a camera rig was attached that held the camera in an almost nadir position.

To obtain the imagery, we utilized a 7 megapixel point \& shot camera (Canon Powershot G6) combined with a 2 gigabyte storage medium. This setting provided us with the ability to obtain 100 raw data images $(*$.crw) per flight session with a resolution of $3072 \times 2304$ pixels and a shooting frequency of one image per minute. The restriction of 100 images was given by the software of the camera. The ground resolution of these imagery depends very much on the flying height of the platform (e.g. $\sim 5 \mathrm{~cm}$ at a flying height of $130 \mathrm{~m}$ above the ground). The total costs for the setup, including the helium, was about $1600 €$.

For further processing, the imagery was georectified using a grid of ground control points (GCPs). The grid had

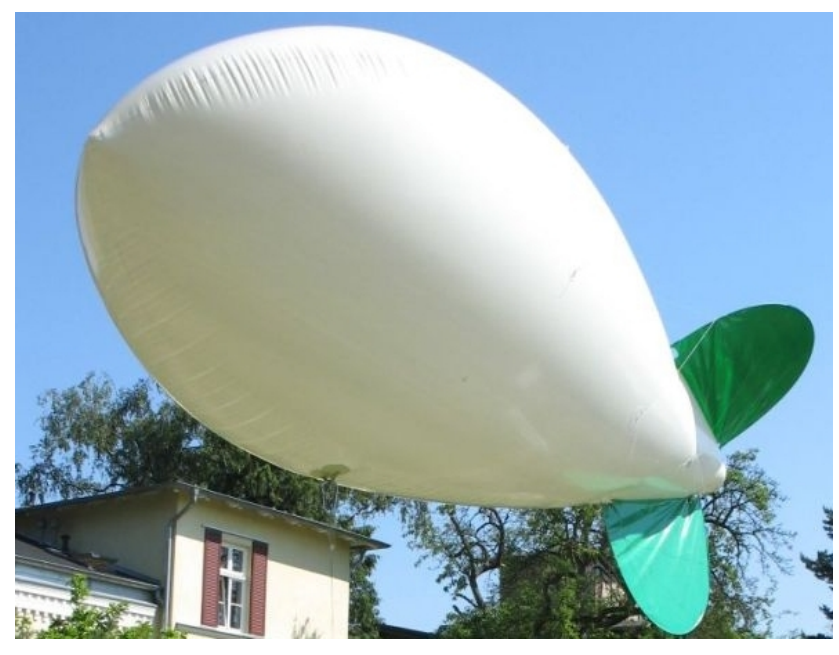

Fig. 2. Helium filled dirigible with tail fins; the envelop is inflated only by the gas pressure.

a cellwidth of about $50 \mathrm{~m}$, and the position of every GCP was measured with a differential global positioning system. The average horizontal accuracy of these measurements was $35 \mathrm{~cm}$.

In order to get a reasonable amount of GCPs for georectification and at the same time a very high ground resolution, a flying height of $\sim 150 \mathrm{~m}$ above the ground was chosen, offering a ground resolution of about $6 \mathrm{~cm}$ and a minimum of 6 GCPs in every image.

To simulate different flying heights of the dirigible, we coarsened the ground resolution from $6 \mathrm{~cm}$ to $10 \mathrm{~cm}$ and further in steps of $5 \mathrm{~cm}$ up to a resolution of $100 \mathrm{~cm}$. By coarsening the resolution up to $100 \mathrm{~cm}$ we cover the range from very high resolution airborne imagery to very high resolution commercial satellite imagery (e.g. QuickBird $2(61 \mathrm{~cm})$ and IKONOS $2(100 \mathrm{~cm}))$. Coarsening the resolution was 


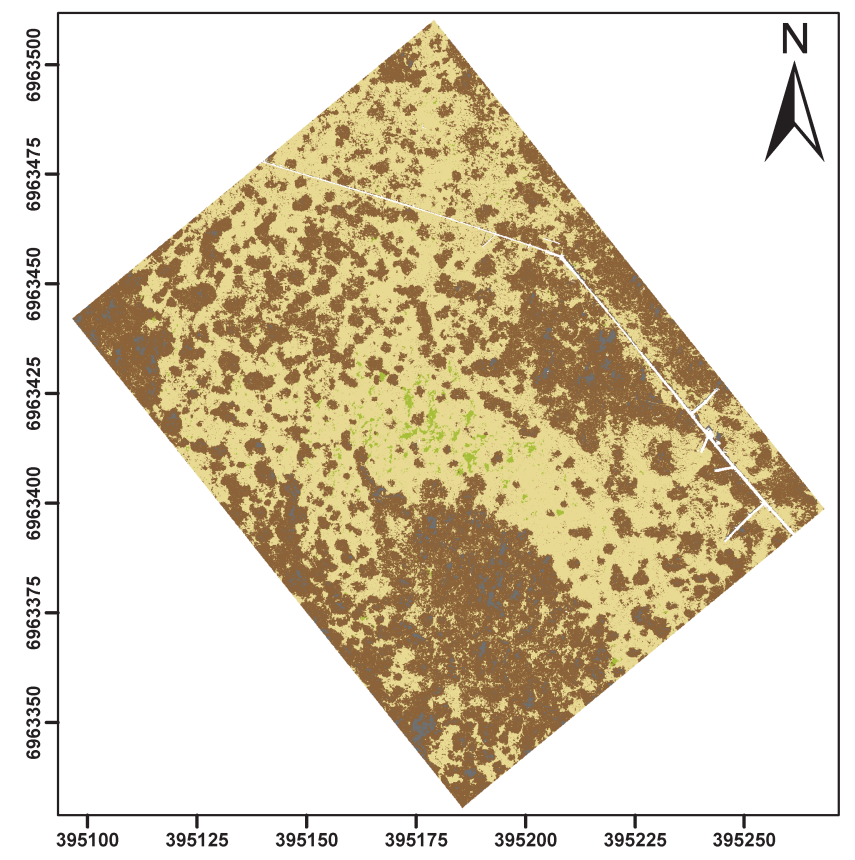

Fig. 3. Result of the maximum likelihood classification at a ground resolution of $6 \mathrm{~cm}$; green=flarks, beige=lawns, brown=hummocks, dark gray=shadow, white=boardwalk and dead trees; data are presented in the coordinate system of UTM zone $36 \mathrm{~N}$, WGS 84, unit=meter.

done during the process of georectification in ER Mapper Professional 7.1 of ER Mapper, using the nearest neighbor algorithm to resample the imagery to the desired resolution. We used the nearest neighbor resampling because it is copying actual data values of the closest datapoint to the cell in the output dataset and does not alter the original input pixel values (Lillesand and Kiefer, 1994). Resampling of multispectral imagery using the nearest neighbor algorithm preserves the relationship between the different bands of the image (Earth Resource Mapping, 2006).

The georectified imagery was classified in the next step, defining training areas with the typical spectral characteristics of the micro-site types and using a supervised classification with the maximum likelihood algorithm in ER Mapper 7.1 to search for all other pixels with similar spectral characteristics (Lillesand and Kiefer, 1994). The resulting land cover map (Fig. 3) was vectorized, using the Raster-ToPolygon function with the option No_Simplify in ArcGIS of ESRI (ESRI, 2004) to assure that the polylines of the output polygone conformed to the input raster's cell edge. Vectorization was necessary to determine the object size of a single object or the mean object size of the different micro-site types. Furthermore, we calculated total area and average size of each micro-site type for each resolution (Fig. 4).

The overal accuracy of the classification result is ca. $84 \%$. The accuracy assessment was conducted using a subset of a vegetation survey done in July 2005 at the covered GCPs

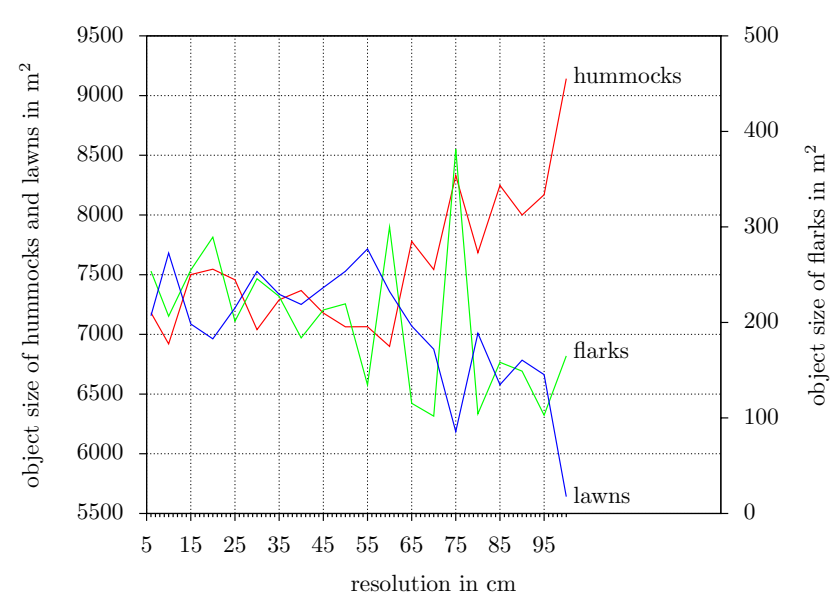

Fig. 4. Estimated total areas for flarks, lawns and hummocks at a stepwise coarsened ground resolution from $6 \mathrm{~cm}$ to $100 \mathrm{~cm}$. The size of micro-sites is changing on a wide amplitude with changing resolution. Note different y-axes for hummocks/lawns and flarks, respectively.

$(n=6)$ and within the covered frames for gas measurements $(n=12)$.

To identify possible thresholds for the detection of large changes in the calculated area during the coarsening process and thus reasonable object sizes at the particular resolution (Fig. 5), we used the moving split window analysis (MSWA) e.g. Webster and Wong (1969). A four-sample window width was applied to find possible thresholds while coarsening the ground resolution. For every half of the window the arithmetic mean of the area was calculated and the difference between halves determined. The window was moved sequentially through the data to achieve statistical comparison for the entire data set. Using the moving split window, a change of the observed attribute is indicated by maximum values in the graphs (Johnston et al., 1992). The calculation of the coverage of different micro-site types at a given resolution was possible due to the vectorization of the classification output. The vectorization allows to seperate objects of the same classes from each other and the calculation of spatial coverage for every object.

\section{Results}

Highest obtained ground resolution was $6 \mathrm{~cm}$ and subsequent coarsening resulted in 20 area estimates (Fig. 4) for each micro-site type. Flark area was unstable above a threshold of $\sim 25 \mathrm{~cm}$ from where it decreased with coarsening resolution (loss of $54 \%$ between $6 \mathrm{~cm}$ and $100 \mathrm{~cm}$ ) with the exception of the resolution between $55 \mathrm{~cm}$ and $80 \mathrm{~cm}$, were values for flarks varied by up to $370 \%$. Area of lawns and hummocks were unstable at a threshold of $\sim 60 \mathrm{~cm}$ and above. Below the mentioned thresholds the values varied around $7250 \mathrm{~m}^{2}$ $( \pm 10 \%)$ for hummocks/lawns and around $240 \mathrm{~m}^{2}( \pm 20 \%)$ 


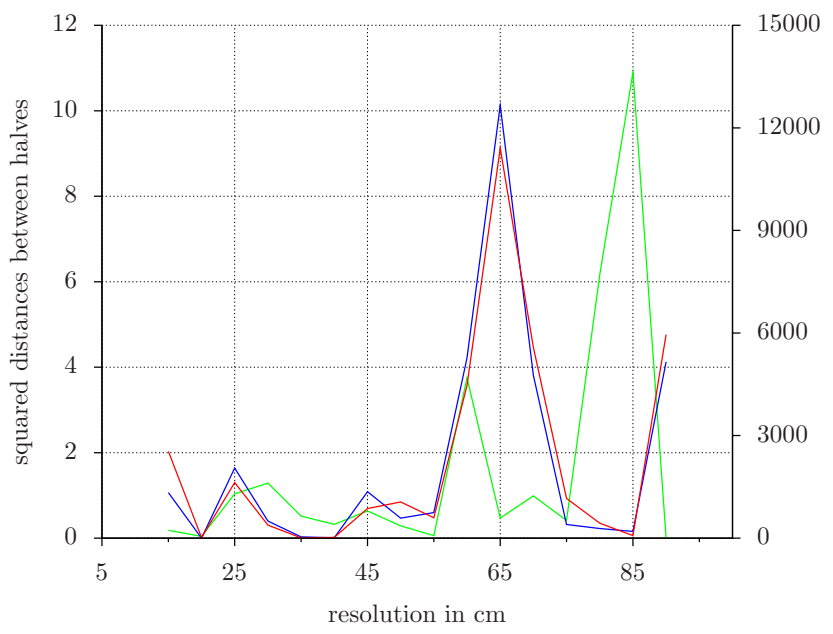

Fig. 5. Moving split window analysis of the total area covered by flarks, lawns and hummocks; the squared distances between the halves of the windows (y-axes) is plotted against the resolution ( $\mathrm{x}$ axes); the plot is showing the combined result of all three microsites, where the left y-axis belongs to lawn (blue) and hummocks (red) and the right y-axis to the flarks (green). Values on the left axis have to be multiplied by 100000 .

for flarks, respectively. Hence we called the range below the thresholds "stable" (Fig. 4). This observation was confirmed by the result of the MSWA, where the peaks indicated possible thresholds at $25 \mathrm{~cm}$ and $65 \mathrm{~cm}$ (Fig. 5) for either flarks or lawns and hummocks.

Coarser resolutions resulted in a linear increase of hummocks and a concurrent decrease in lawns ( $21 \%$ change between $6 \mathrm{~cm}$ and $100 \mathrm{~cm}$ ). The large fluctuation in the class of flarks between a resolution of $55 \mathrm{~cm}$ and $80 \mathrm{~cm}$ is showing the unreliability of the data at these resolution. In comparison to these uncertainties, Fig. 5 is showing a threshold for the class of flarks at a resolution of $60 \mathrm{~cm}$. Due to the small contribution of flarks to the total area, estimates of lawns and hummocks behave nearly as mirror images of each other (Fig. 4). The amount of single objects in the classes of lawns and hummocks and their close spatial relationship is causing a give-and-take between these two classes at their common border. Hence the spatial representation of the two major classes depend on each other and a changing of much smaller classes has no substantial effect.

Seasonal gas fluxes differed between micro-site types (Table 2) with flarks emitting the most $\mathrm{CH}_{4}$ per area and hummocks taking up most of the $\mathrm{CO}_{2}$ per area. Seasonal DOC export was calculated as $0.09 \pm 0.02 \mathrm{~g} \mathrm{C} / \mathrm{m}^{2}$, representing only $0.23 \%$ of the seasonal carbon balance. Taken together, the generalizations in lower resolution imagery led to biased area estimates for the individual micro-site types (Fig. 4), and thus at a resolution of $100 \mathrm{~cm}$ to an overestimation of total $\mathrm{CO}_{2}$ uptake of $\sim 5.2 \%$ (Fig. 6a) and an underestimation of total $\mathrm{CH}_{4}$ emission of $\sim 6.2 \%$ (Fig. $6 \mathrm{~b}$ ).
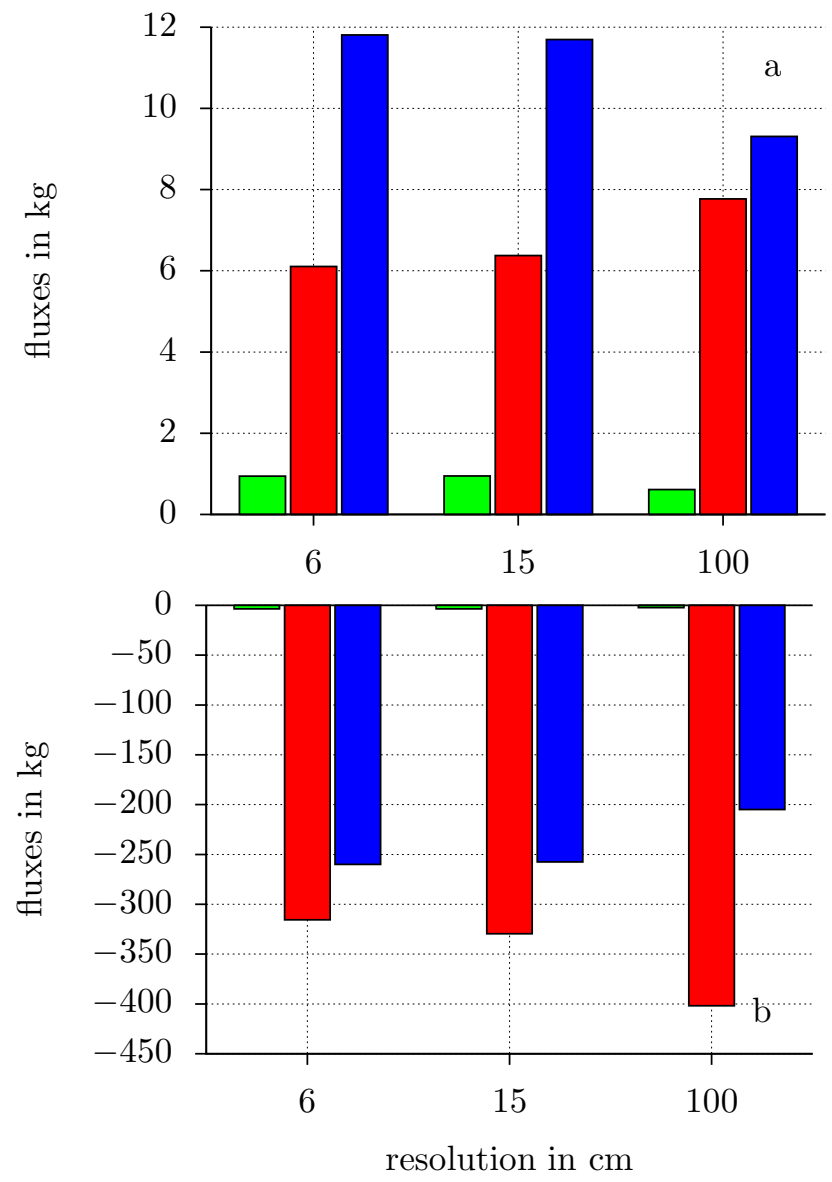

Fig. 6. Seasonal gas fluxes, calculated for the area of every microsite type (green=flarks, blue=lawns, red=hummocks) at changing resolutions; (a) seasonal fluxes of $\mathrm{CH}_{4}-\mathrm{C}$, grouped by resolution; at a resolution of $100 \mathrm{~cm}$ an underestimation of $\sim 6 \%$ of the total $\mathrm{CH}_{4}-$ $\mathrm{C}$ emission is shown; (b) fluxes of $\mathrm{CO}_{2}-\mathrm{C}$, grouped by resolution; using a resolution of $100 \mathrm{~cm}$ instead of $6 \mathrm{~cm}$ lead to an overestimation of total $\mathrm{CO}_{2}-\mathrm{C}$ uptake of $\sim 5 \%$.

The accuracy of spatial gas flux estimations in this approach is highly related to the ground resolution of the imagery used for the classification. Due to stronger generalization at a smaller scale the loss of small objects is increasing by coarsening the pixel size.

For every micro-site the lowest possible detection threshold, indicated by the peak, is located at a ground resolution of $25 \mathrm{~cm}$. The next possible threshold for every micro-site is at a ground resolution of $60 \mathrm{~cm}$.

\section{Discussion}

The underestimation of $\mathrm{CH}_{4}$ fluxes at lower resolution, caused by the underestimated area of flarks and lawns, leads to a conservative approximation of the $\mathrm{CH}_{4}$ fluxes in the particular area. Using a ground resolution of $100 \mathrm{~cm}$ the net 
Table 2. Seasonal gas fluxes of $\mathrm{CH}_{4}-\mathrm{C}$ and $\mathrm{CO}_{2}-\mathrm{C}$ for every microsite type ( \pm as the $95 \%$ confidence interval), estimated from closed chamber measurements; the DOC value is an estimate for the complete catchment.

\begin{tabular}{lrrr}
\hline & flarks & lawns & hummocks \\
\hline $\mathrm{CH}_{4}-\mathrm{C}$ & $3.71 \pm 0.06 \mathrm{~g} / \mathrm{m}^{2}$ & $1.65 \pm 0.04 \mathrm{~g} / \mathrm{m}^{2}$ & $0.85 \pm 0.02 \mathrm{~g} / \mathrm{m}^{2}$ \\
$\mathrm{CO}_{2}-\mathrm{C}$ & $-13.82 \pm 0.28 \mathrm{~g} / \mathrm{m}^{2}$ & $-36.33 \pm 0.50 \mathrm{~g} / \mathrm{m}^{2}$ & $-43.95 \pm 0.79 \mathrm{~g} / \mathrm{m}^{2}$ \\
\hline DOC export flux & & $0.09 \pm 0.02 \mathrm{~g} \mathrm{C} / \mathrm{m}^{2}$ & \\
\hline
\end{tabular}

ecosystem carbon uptake is overestimated by $\sim 2.13 \mathrm{~g} / \mathrm{m}^{2}$ $(\sim 5.5 \%)$ in the sample area, compared to the highest resolution of $6 \mathrm{~cm}$. Using land-cover maps with even lower resolutions (Takeuchi et al., 2003), would very likely increase this effect.

The fluctuation of the values in Fig. 4 is very likely the effect of a changing pixel pattern when resampling the imagery. Furthermore, the selection of the training area for the algorithm and the variety of pixel values within this area adds fluctuations to the graphs. The effect that the area estimates of lawns and hummocks behave nearly as mirror images of each other (Fig. 4) is (1) related to the relatively small contribution of flarks to the area and (2) probably also related to the resampling and classification method.

As shown in Fig. 4, the total area of individual micro-site types, depending entirely on the size and number of the associated polygones, is altered with changing resolution. On the one hand, this is caused by the generalization of details from high to lower resolution data (Jensen, 2000). On the other hand, it is more difficult to identify smaller objects at lower resolutions, leading to errors during the classification process (Markham and Townshend, 1981). It is also possible that the classification result is influenced by the data distribution, considering that the maximum likelihood algorithm assumes a normal distribution of the band data (Leica Geosystems GIS and Mapping, 2003).

The result of the MSWA indicates possible thresholds for the resolution of the imagery (Fig. 5). To achieve reasonable classification results in a peatland like Salmisuo a ground resolution of $25 \mathrm{~cm}$ is recommended to analyze small microsites (e.g. flarks). To analyze micro-sites as lawns and hummocks a ground resolution of $60 \mathrm{~cm}$ seems to be adequate. Both thresholds show that very high satellite imagery still tends to misjudge the distribution of the micro-sites (plant communities) in small patterned peatlands.

\section{Conclusions}

We show that based on differing ground resolution of the land-cover map substantially different areas for individual micro-site types are calculated. This influences the calculation of the carbon balance since gas fluxes between the ecosystem and the atmosphere are measured at representative spots of each micro-site type and then multiplied by the micro-site area. In particular small micro-sites, which are often biogeochemical hot-spots, (e.g. wet areas emitting $\mathrm{CH}_{4}$ ), tend to be affected. In our field site, a ground resolution of $25 \mathrm{~cm}$ appears to be necessary for the detection of these biogeochemical hot-spots with respect to $\mathrm{CH}_{4}$ emission. A resolution of $60 \mathrm{~cm}$ appears sufficient for a representative detection of larger micro-site types as well as with respect to $\mathrm{CO}_{2}$ fluxes for all micro-sites types.

Acknowledgements. Funding for this study was provided by a Sofja Kovalevskaja Research Award and two grants from the German Science Foundation (DFG) to M. Wilmking (WI 2680/1-1, WI 2680/2-1). I. Forbrich was supported by a Fellowship from the German Federal Environmental Foundation (DBU). T. Becker was partly supported by the German Academic Exchange Service (DAAD). We thank the Umweltbundesamt for support for B. Thees and all colleagues of the "Carbon in Peatlands" Conference in Wageningen for helpful discussions. Furthermore, we like to thank A. Roberts of the S. Fraser University in Burnaby, Canada for the use of his remote sensing laboratory and S. Wolf of the ETH Zurich, Switzerland for the generative and enjoyable discussions.

Edited by: T. R. Christensen

\section{References}

Alm, J., Talanov, A., Saarnio, S., Silvola, J., Ikkonen, E., Aaltonen, H., Nykänen, H., and Martikainen, P. J.: Reconstruction of the carbon balance for microsites in a boreal oligotrophic pine fen, Finland, Oecologia, 110, 423-431, 1997.

Bubier, J., Moore, T., Savage, K., and Crill, P.: A comparison of methane flux in a boreal landscape between a dry and a wet year, Global Biogeochem. Cy., 19, GB1023, doi:10.1029/ 2004GB002351, 2005.

Earth Resource Mapping: ER Mapper Professional 7.1 Tutorial, Earth Resource Mapping, San Diego, CA, 2006.

ESRI: ArcGIS 9 - Geoprocessing Commands, Quick Reference Guide, ESRI, Redlands, CA, 2004.

Finnish Meteorological Institute: Climatic Statistics of Finland, 2002.

Jensen, J. R.: Remote sensing of the environment: an earth resource perspective, Prentice-Hall Inc., 2000.

Johnston, C. A., Pastor, J., and Pinay, G.: Landscape Boundaries: Consequences for Biotic Diversity and Ecological Flows, chap. Quantitative Methods for Studying Landscape Boundaries, Springer-Verlag New York, Inc, 107-125, 1992.

Kettunen, A.: Short-term carbon dioxide exchange and environmental factors in a boreal fen, Verh. Internat. Verein. Limnol., 27, 1-5, 2000.

Kutzbach, L., Schneider, J., Sachs, T., Giebels, M., Nykänen, H., Shurpali, N. J., Martikainen, P. J., Alm, J., and Wilmking, M.: $\mathrm{CO} 2$ flux determination by closed-chamber methods can be seriously biased by inappropriate application of linear regression, Biogeosciences, 4, 1005-1025, 2007a, http://www.biogeosciences.net/4/1005/2007/. 
Kutzbach, L., Wille, C., and Pfeiffer, E. M.: The exchange of carbon dioxide between wet arctic tundra and the atmosphere at the Lena River Delta, Biogeosciences, 4, 869-890, 2007b, http://www.biogeosciences.net/4/869/2007/.

Laine, A., Sottocornola, M., Kiely, G., Byrne, K. A., Wilson, D., and Tuittila, E. S.: Estimating net ecosystem exchange in a patterned ecosystem: Example from blanket bog, Agr. Forest Meteorol., 18, 231-243, 2006.

Leica Geosystems GIS and Mapping: Erdas Imagine 8.7 Field Guide, Leica Geosystems GIS and Mapping LLC, Atlanta, GA, 2003.

Lillesand, T. M. and Kiefer, R. W.: Remote Sensing and Image Interpretation, John Wiley \& Sons, Inc., third edn., 1994.

Markham, B. L. and Townshend, J. R. G.: Land cover classification accuracy as a function of sensor spatial resolution, in: Proceedings 15th International Symposium on Remote Sensing of Environment, 1075-1090, 1981.

Riutta, T., Laine, J., Aurela, M., Rinne, J., Vesela, T., Laurila, T., Haapanala, S., Pihlatie, M., and Tuittila, E. S.: Spatial Variation in Plant Community Functions Regulates Carbon Gas Dynamics in a Boreal Fen Ecosystem, Tellus B, 59, 838-852, 2007.
Saarnio, S., Alm, J., Silvola, J., Lohila, A., Nykänen, H., and Martikainen, P. J.: Seasonal variation in $\mathrm{CH} 4$ emissions and production and oxidation potentials at microsites on an oligotrophic pine fen, Oecologia, 110, 414-422, doi:10.1007/ s004420050176, 1997.

Schimel, D. S. and Potter, C. S.: Biogenic trace gases: measuring emissions from soil and water, chap. Process modelling and spatial extrapolation, pp. 358-383, Blackwell Science, Cambridge, Massachusetts, USA, 1995.

Strahler, A. and Strahler, A.: Physical Geography: Science and Systems of the Human Environment, John Wiley \& Sons, Inc., 2005.

Takeuchi, W., Tamura, M., and Yasuoka, Y.: Estimation of methane emission from West Sibirian wetland by scaling technique between NOAA AVHRR and SPOT HRV, Remote Sens. Environ., 81(1), 21-29, 2003

Webster, R. and Wong, I. F. T.: A numerical procedure for testing soil boundaries interpreted from air photographs, Photogrammetria, 24, 59-72, 1969. 